\title{
An International Comparison of Equity in Accessibility to Jobs: London, São Paulo and the Randstad
}

\author{
John P. Pritchard ${ }^{1}$ (D), Diego Tomasiello ${ }^{2}$, Mariana Giannotti ${ }^{2}$, Karst Geurs ${ }^{1}$ \\ ${ }^{1}$ Centre for Transport Studies, University of Twente, ${ }^{2}$ Polytechnic School, University of São Paulo \\ Keywords: Iondon, randstad, são paulo, palma ratio, gini coefficient, equity, potential accessibility \\ https://doi.org/10.32866/7412
}

Transport Findings

\begin{abstract}
We analyze the impact of different accessibility measures on the interpretation of associated equity analysis using the Gini Coefficient and the (pseudo) Palma Ratio, and the impact of the method of assigning zonal accessibility on Gini estimation results using four different alternatives. Two types of potential accessibility measures (zonal and person-based) and two ratios of potential jobs to potential population (intra-modal and multi-modal) are estimated for car and transit in the Netherlands' Randstad region, Greater London, and São Paulo relying on network data, schedule-based data, and speed profiles. Gini results are heavily influenced by the accessibility indicator and the method of assignment. The Palma ratio is also influenced by the choice of accessibility indicator, with the person-based potential accessibility measure tending to show greater inequity.
\end{abstract}

\section{RESEARCH QUESTION AND HYPOTHESES}

We examine job accessibility during the morning peak period in the Netherlands' Randstad region (NLR), Greater London, England (GL), and the municipality of São Paulo, Brazil (SP). Comparing accessibility inequalities across metropolitan regions and countries with very different spatial-infrastructural and socioeconomic conditions is challenging. There are many different definitions and approaches to measure accessibility and equity, and there is no agreement over which is best; all have specific limitations. The aim of this article is not to solve this debate but to understand how the choice and operationalization of well-known indicators affect conclusions on inequalities in accessibility for different metropolitan regions. We estimate two accessibility indexes and two equity measures for two transport modes (car and transit), using different operationalizations.

\section{METHODS AND DATA}

Table 1 presents the indicators applied in the analysis.

We calculate potential accessibility to jobs during the morning peak period following the general gravitational form proposed by (Hansen 1959) (Table 1-1a). To weigh the jobs, we estimate an average (all modes) decay function for each city-region based on commuting origin-destination data (GL: Commute flow data (ONS 2015); NLR: National travel survey ([OViN] 2010-2014 and C.B.S., n.d.) SP: origin-destination survey 2007 (Metrô São Paulo 2012)), selecting the best fit with the Akaike information criterion: GL (log-logistic -6.826, 2.478), NLR (log-logistic $\alpha=-7.485, \beta=2.254)$, and SP (negative exponential $\alpha=-0.026$ ). We do not use mode-specific functions 


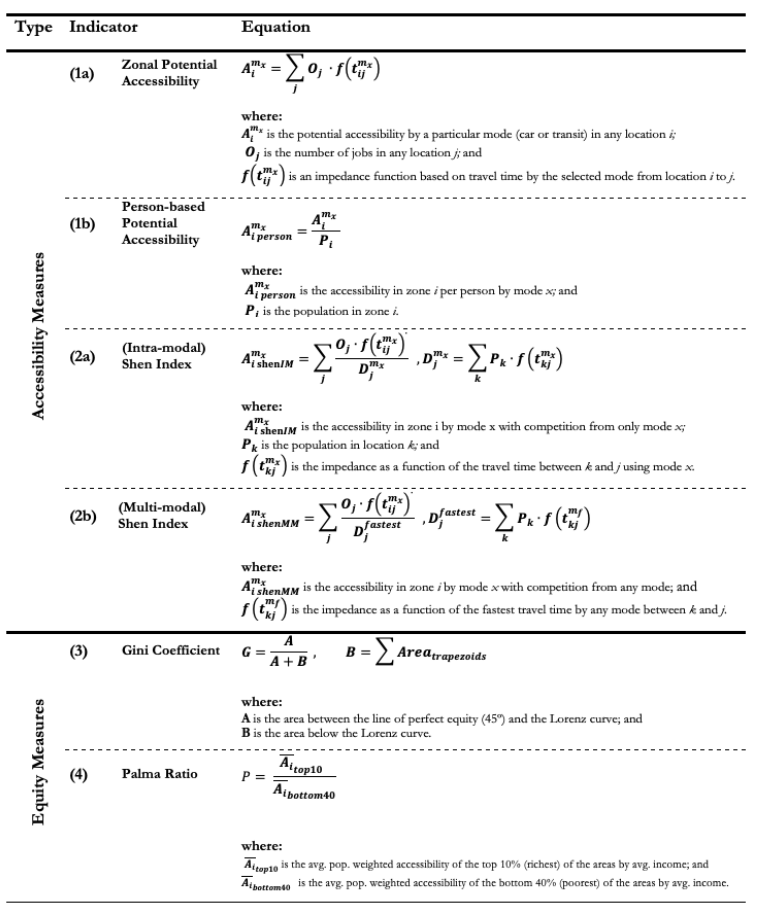

Table 1: Accessibility and Equity Indicators

because they are ill-suited for cross-modal comparisons of absolute values of accessibility (Geurs and Eck 2001). Using different values would likely bias the results by capturing a "willingness" to travel further by transit that is often the result of restricted choices.

Because the city-regions have different total volumes of opportunities and working-age population (see Table 2), we also estimate a person-based potential accessibility (Table 1-1b) and use the (Shen 1998) index, which includes competition for opportunities at destinations $j$. This index provides a ratio between the accessible jobs and the population that can reach said jobs using a decay or impedance function for both. The previously fitted decay functions are applied. We estimate two variations: an intra-modal (i.e., mode-specific) index (Table 1-2a) using formula 2 in (Shen 1998), and another that considers the greatest competition from any area by any mode. The first accounts for the competition using only the selected mode of travel (e.g., for transit, only transit completion is considered). The multi-modal index suggested here provides a broader lens of the potential competition without requiring the modal split to be known. As can be seen in Table 1-2b, the index is calculated for each mode, but the largest potential competition is considered regardless of the mode used. The denominator, which accounts for population, uses the fastest travel time alternative between each origin-destination pair (i.e., the greatest possible competition from each zone $k$ to any zone $j$ ). This means that if the travel time by car is faster than transit from zones $k$ to $j$ (i.e., more workers can reach the opportunities at $j$ ), then the travel time by car is selected for this particular origin-destination pair. This is a good indicator, because like 


\begin{tabular}{|c|c|c|c|}
\hline & $\mathrm{SP}$ & GL & NLR \\
\hline Zone Types & Origin-destination subzones & Transport for London zones & 4-digit postcodes \\
\hline Zones (n) & 1,308 & 3,289 & 1,031 \\
\hline After listwise deletion ${ }^{a}$ & 1,286 & 3,134 & 9,72 \\
\hline Total Area $\left(\mathrm{km}^{2}\right)$ & $1,521 \mathrm{~km}^{2}$ & $1,572 \mathrm{~km}^{2}$ & $5,327 \mathrm{~km}^{2}$ \\
\hline Total Population $(16-64)^{b}$ & $7,805,636$ & $5,440,207$ & $5,305,710$ \\
\hline Total Jobs ${ }^{c}$ & $4,729,358$ & $3,917,847$ & $3,582,596$ \\
\hline
\end{tabular}

potential accessibility, it focuses on the supply side of accessibility and does not assess the modal choice of individual residents; the greatest potential competition from any area $k$ is considered.

${ }^{a}$ Listwise deletion is used in the analysis (i.e., only areas with population and average income data are included).

b GL: Small area pop. estimates 2011 (ONS 2018); NLR: Postcode pop. estimates 2015 (CBS 2016); SP: Census 2010 (IBGE 2010).

c GL: NS-SEC 2011 (ONS 2017); NLR: LISA 2014 (Stichting 2014); SP: RAIS 2009 + CNEFE 2010 (García-López and Moreno-Monroy 2016).

General Transit Feed Specification (GTFS) is used to estimate transit travel time matrices for SP (with automatic vehicle location corrections) and the NLR every 15 minutes during the morning peak (6:00 a.m. to 9:00 a.m.). For GL, WebCAT Time Mapping (GLA 2015) is used because GTFS was not available. This could affect the comparison of transit accessibility between the city-regions, although the impact should be limited because all the measured times are based on schedule data provided by the transit agencies (albeit in different formats), and the same walking speeds are used. Additionally, the results remain internally consistent (i.e., there is no reason to assume that the TIM estimates are more internally biased than the GTFS estimates for the other case studies). We estimate car travel times using Tom Tom historical speed profiles, accounting for congestion and following the approach discussed in (Moya-Gómez and Geurs 2018). Note that for GL, car travel times will reflect the impact of the London congestion charge, but toll fees are not included in the analysis.

We estimate the Gini coefficient (Gini 1936) to measure the distribution of accessibility (not income) for the population and for geographic areas using the graphical (trapezoidal) Lorenz curve approximation following the formula in Table 1-3. The Gini coefficient has been widely applied in transportation analyses; however, the interpretation for accessibility is fundamentally different from that of income due to units being counted more than once (Lucas, van Wee, and Maat 2015). We test four different methods for including zonal potential accessibility values in the Gini estimation: two for population and 
two for geographic areas. The key difference is related to how the zonal values are interpreted. Method 1 calculates the geographic distribution of zonal accessibility between the zones of analysis. Method 2 calculates the distribution of accessibility among the population assigning the full values of the zonal accessibility to each resident within these zones. Method 3 calculates the distribution among the population of the person-based accessibility ( $\mathrm{Ai} / \mathrm{pop})$, while method 4 calculates the same distribution but for the zones.

The Palma ratio (Palma 2011) is less common in transportation research, but it can be argued that it more accurately reflects the societal picture by focusing on the extremes (Banister 2018). We estimate this following the method proposed in (Guzman and Oviedo 2018), ranking areas by (average zonal) income deciles (GL: household income estimates for small areas 2011 (GLA 2015); NLR gross household income by area 2014 (CBS 2016); SP: income census 2010 (IBGE 2010)), and calculating population weighted average accessibilities using the formula in Table 1-4. Unlike the Gini coefficient which assesses the egalitarian distribution of accessibility but does not provide any insight into the areas or population groups with higher or lower levels of accessibility, the Palma ratio provides a way to compare the accessibility of the richest decile to the four poorest deciles. Values greater than 1 correspond to situations where the top income decile has higher average accessibility than the lowest income deciles.

\section{FINDINGS}

Main results can be found in Table 3. The car provides, on average, higher zonal potential accessibility to the residents of all three city-regions (see Figure 1 for the spatial pattern); SP has the highest average accessibility by car and transit, and GL has the lowest. However, the person-based potential measure shows that the car provides access to 477 jobs per resident in GL, 409 in SP, and 355 in the NLR. Transit provides access to 116, 144, and 37 jobs per resident, respectively.

The analysis of the Shen indexes (see Figure 2) highlights the vastly different spatial patterns of the car and transit. The richest accessibility areas by transit are in the centers of the cities, while the car is more evenly distributed. Job competition for transit users increases strongly if we allow competing workers to use the fastest transport mode, not just the selected mode of travel. Clearly, the car greatly outperforms transit in all three cases, with the index for the car being highest in the NLR and lowest in SP.

In terms of the distribution, the Gini results are heavily influenced by the choice of accessibility indicator and by how the area-based values are assigned to the population. Methods 1 and 4 provide territorial distribution but are not ideal because they do not consider the population of the areas during the aggregation. Methods 2 and 3 are more appropriate and account for the population. They show that the accessibility by car tends to be better spatially distributed than the accessibility by transit. However, the way in which the 


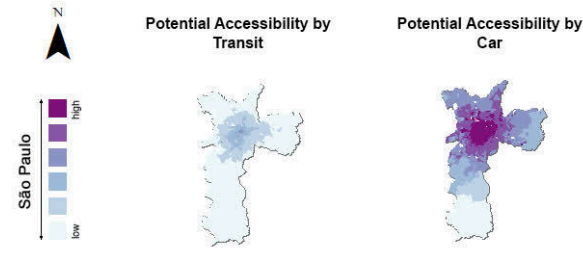

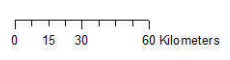

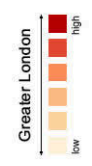
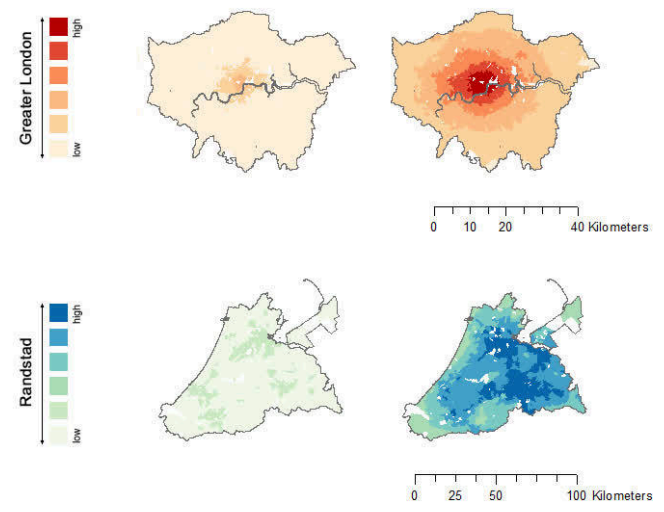

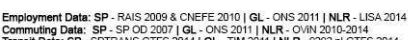

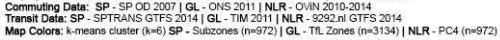

Figure 1: Potential Job Accessibility

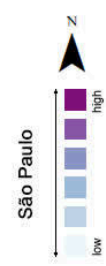

Shen Index - mode specific

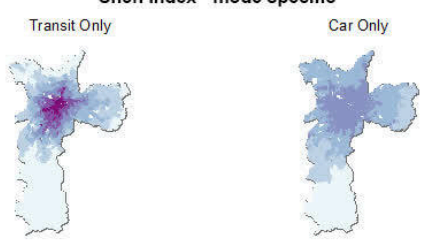

Shen Index - best alternative Transit

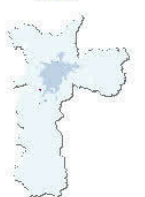

Car
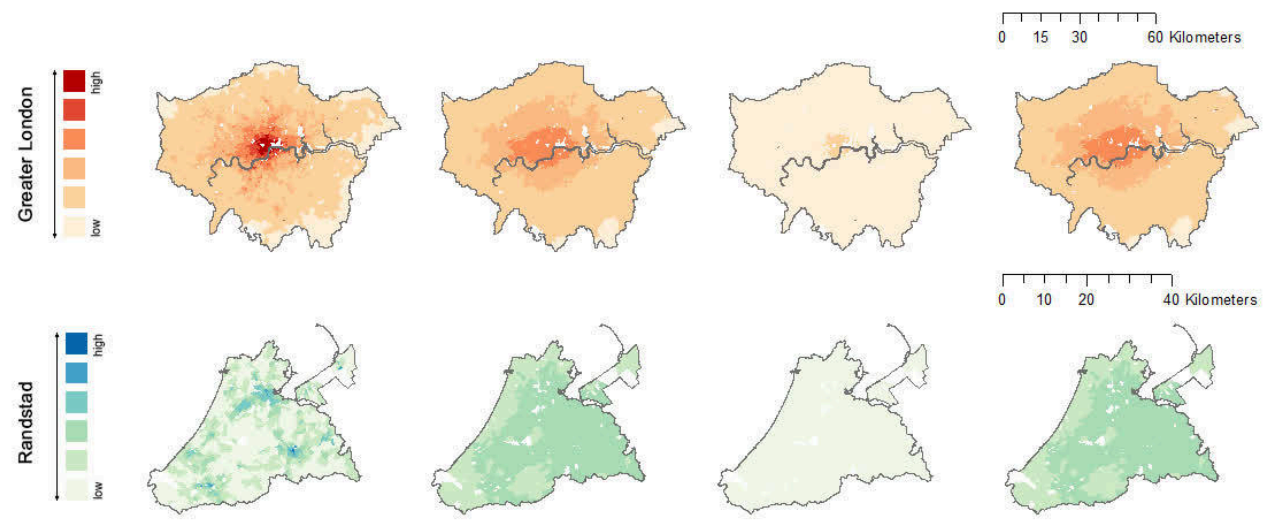

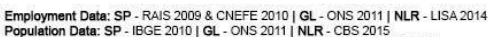

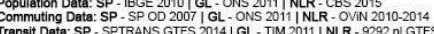

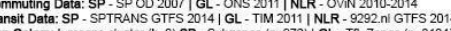
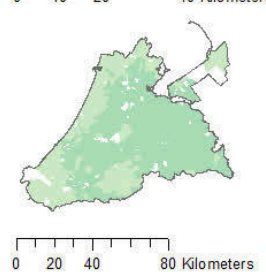

Figure 2: (Pseudo) Shen Accessibility 


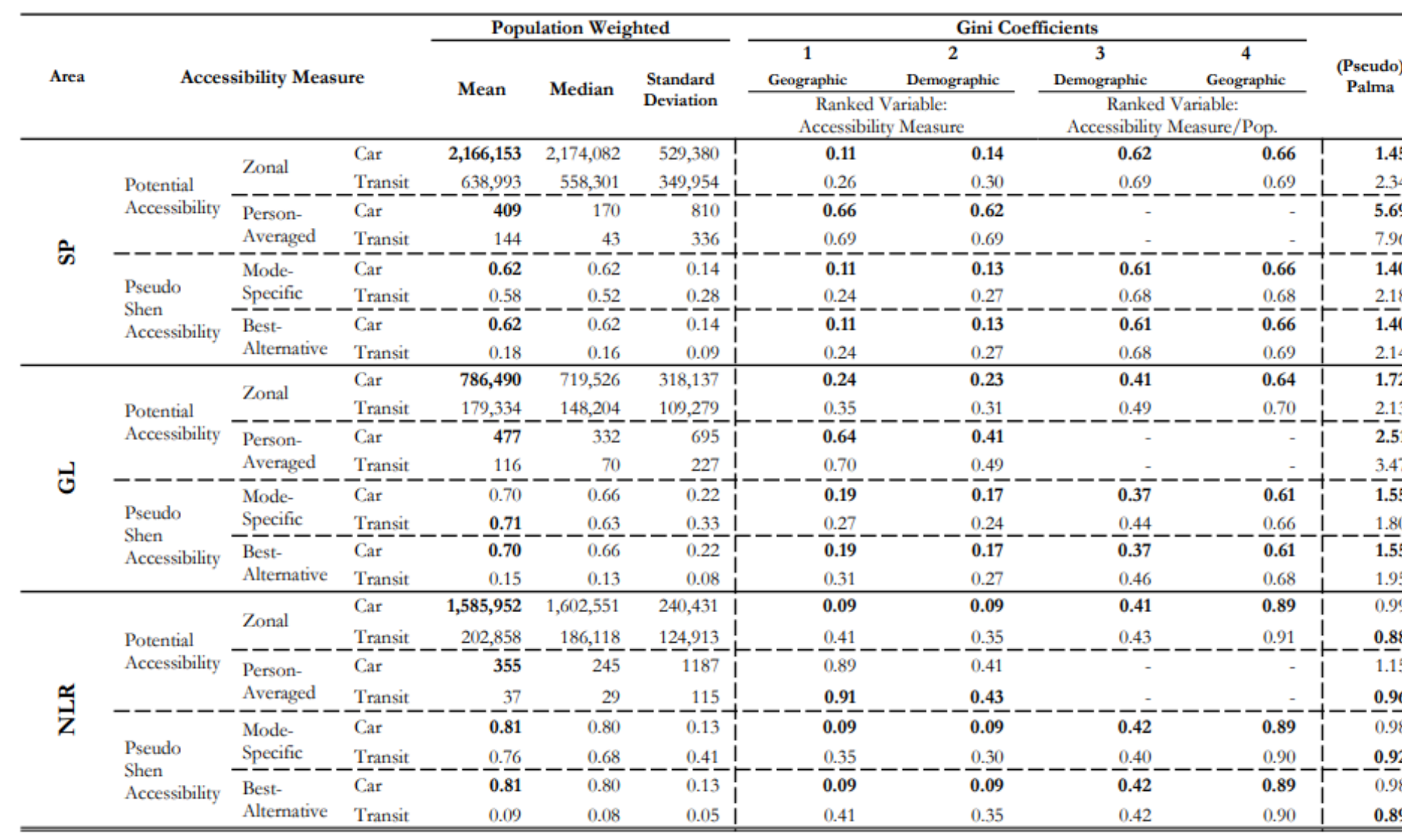

Table 3: Accessibility and Equity Results

coefficient is applied results in vastly different outcomes. Person-based accessibility tends to show greater inequalities in the case studies. Having said this, if the same methodology and accessibility indicator is used, a comparison between cities is possible and is particularly useful for cross-modal analysis. However, a clear methodological description should be provided.

The Palma ratio is also influenced by the choice of accessibility indicator, with the person-based potential accessibility measure tending to show greater inequity. SP shows the greatest inequity by transit, and the transit inequity is greater than that of the car. This is particularly problematic because it means that residents in lower income areas are even more disadvantaged by transit than by car, despite being more likely to use transit. In the NLR, the lowest income groups have on average better accessibility by transit than their higher income counterparts. This is likely due to the fact that many of the lower income areas tend to be more central than in SP, where they can be found in the periphery of the municipality. 


\section{ACKNOWLEDGMENTS}

As part of the ASTRID project, this work has been funded by the Netherlands Organisation for Scientific Research (NWO Project number: 485-14-038) within the framework of the joint FAPESP-ESRC-NWO Joint Call for Transnational Collaborative Research Projects Sustainable Urban Development.

Diego Tomasiello and Mariana Giannotti would like to acknowledge the support from the Coordenação de Aperfeiçoamento de Pessoal de Nível Superior-Brasil (CAPES) (Finance Code 001), CAPES process number 1577479, and CNPq process number 310908/2017-5. 


\section{REFERENCES}

Banister, D. 2018. Inequality in Transport. Marcham, UK: Alexandrine Press.

CBS. 2016. "Bevolking En Huishoudens; Viercijferige Postcode, 1 Januari 2015.” 2016. https://www.cbs.nl/nl-nl/maatwerk/2016/04/bevolking-en-huishoudens-viercijferigepostcode-1-januari-2015.

García-López, M.Á., and A.I. Moreno-Monroy. 2016. "Income Segregation and Urban Spatial Structure: Evidence from Brazil (CAF Development Bank of Latin America).”

Geurs, K.T., and J.R. Eck. 2001. Accessibility Measures: Review and Applications. Bilthoven: National Institute of Public Health and the Environment.

Gini, C. 1936. On the Measure of Concentration with Special Reference to Income and Statistics. Vol. 208. General Series. Colorado College Publication.

GLA. 2015. “Household Income Estimates for Small Areas.” 2015. https://data.london.gov.uk/ dataset/household-income-estimates-small-areas.

Guzman, Luis A., and Daniel Oviedo. 2018. "Accessibility, Affordability and Equity: Assessing 'pro-Poor' Public Transport Subsidies in Bogotá.” Transport Policy 68 (September): 37-51. https://doi.org/10.1016/j.tranpol.2018.04.012.

Hansen, W.G. 1959. “How Accessibility Shapes Land-Use.” Journal of American Institute of Plannners 25: 73-76.

IBGE. 2010. “Censo Demográfico 2010.” 2010. https://ww2.ibge.gov.br/home/estatistica/ populacao/censo2010/default.shtm.

Lucas, Karen, Bert van Wee, and Kees Maat. 2015. "A Method to Evaluate Equitable Accessibility: Combining Ethical Theories and Accessibility-Based Approaches.” Transportation 43 (3): 473-90. https://doi.org/10.1007/s11116-015-9585-2.

Metrô São Paulo. 2012. "Banco de Dados Das Pesquisas Orgim e Destino Anteriores: 1977 a 2007 e Pesquisa Mobilidade 2012.” 2012. http://www.metro.sp.gov.br/pesquisa-od/resultado-daspesquisas.aspx.

Moya-Gómez, Borja, and Karst T. Geurs. 2018. "The Spatial-Temporal Dynamics in Job Accessibility by Car in the Netherlands during the Crisis." Regional Studies, December, 1-12. https://doi.org/10.1080/00343404.2018.1538554.

ONS. 2015. “Origin and Destination Data 2011.” 2015. https://www.ons.gov.uk/census/ 2011census/2011censusdata/originanddestinationdata.

-__. 2017. "The National Statistics Socio-Economic Classification (NS-SEC).” 2017. https://www.ons.gov.uk/methodology/classificationsandstandards/otherclassifications/ thenationalstatisticssocioeconomicclassificationnssecrebasedonsoc2010.

- - - 2018. "Lower Layer Super Output Area Population Estimates (Supporting Information.” 2018. https://www.ons.gov.uk/peoplepopulationandcommunity/populationandmigration/ populationestimates/datasets/lowersuperoutputareamidyearpopulationestimates.

[OViN] 2010-2014, and C.B.S. n.d. "Onderzoek Verplaatsingen in Nederland (OViN).” https://www.cbs.nl/nl-nl/onze-diensten/methoden/onderzoeksomschrijvingen/korteonderzoeksbeschrijvingen/onderzoek-verplaatsingen-in-nederland--ovin--. 
Palma, José Gabriel. 2011. "Homogeneous Middles vs. Heterogeneous Tails, and the End of the 'Inverted-U': It's All About the Share of the Rich.” Development and Change 42 (1): 87-153. https://doi.org/10.1111/j.1467-7660.2011.01694.x.

Shen, Q. 1998. "Location Characteristics of Inner-City Neighborhoods and Employment Accessibility of Low-Wage Workers." Environment and Planning B: Planning and Design 25 (3): 345-65. https://doi.org/10.1068/b250345.

Stichting, Lisa. 2014. "Landelijk InformatieSysteem van Arbeidsplaatsen (LISA.” 2014. https://www.lisa.nl/home. 